Full length article

\title{
Effect of dietary prebiotics and probiotics on snakehead (Channa striata) health: Haematology and disease resistance parameters against Aeromonas hydrophila
}

\author{
Mohammad Bodrul Munir ${ }^{\mathrm{a}, *}$, Roshada Hashim ${ }^{\mathrm{b}}$, Siti Azizah Mohd Nor ${ }^{\mathrm{c}}$, Terence L. Marsh ${ }^{\mathrm{d}}$ \\ ${ }^{a}$ Faculty of Resource Science and Technology, Univeriti Malaysia Sarawak, 94300 Kota Samarahan, Sarawak, Malaysia \\ ${ }^{\mathrm{b}}$ Faculty of Science and Technology, Universiti Sains Islamic Malaysia, 71800 Bandar Baru Bangi, Malaysia \\ ${ }^{\mathrm{c}}$ Institute of Marine Biotechnology, Universiti Malaysia Terengganu, 21300 Kuala Terengganu, Terengganu, Malaysia \\ d Department of Microbiology and Molecular Genetics, Biomedical \& Physical Sciences, Michigan State University, 567 Wilson Road, East Lansing, MI 48824, USA
}

\section{A R T I C L E I N F O}

\section{Keywords:}

Prebiotics

Probiotics

Haematological parameters

Immunological blood parameters

Pathogenic bacteria (Aeromonas hydrophila)

Snakehead (Channa striata)

\begin{abstract}
A B S T R A C T
This study examined the effect of dietary prebiotics and probiotics after 16 weeks, followed by 8 weeks of post feeding trial with the control unsupplemented diet on haematological and immune response against Aeromonas hydrophila infection in Channa striata fingerlings. Fish were raised on a $40 \%$ protein and $12 \%$ lipid feed containing three commercial prebiotics ( $\beta$-glucan, GOS or galacto-oligosaccharide, MOS or mannan-oligosaccharide); and two probiotics- (Saccharomyces cerevisiae, Lactobacillus acidophilus), respectively and a control. Throughout the study, supplementation with dietary prebiotics and probiotics led to significant $(\mathrm{P}<0.05)$ improvement in the red blood cells, white blood cells, packed cell volume, haemoglobin concentration and serum protein level and lysozyme activities; and these improvements were effective significantly $(\mathrm{P}<0.05)$ when the fish were challenged with Aeromonas hydrophila at the dose of $2 \times 10^{6}$. The disease resistance against A. hydrophila was higher significantly $(\mathrm{P}<0.05)$ in fish fed with probiotic feed supplements (L.acidophilus was highest) compared to prebiotics and control. The study is the first to report the absence of differences in sustaining the efficacies attained after intake of $\beta$-glucan, GOS and MOS upon post-feeding with an unsupplemented feed, over a prolonged period.
\end{abstract}

\section{Introduction}

The increasing intensification and commercialization of aquaculture systems has accelerated the outbreak of diseases that are responsible for huge fish losses [8]. Intensified aquaculture of the Asian snakehead, Channa striata [7] is faced with similar problems associated with the deterioration of water quality and diseases outbreak [17,20,47]. The bottom-living habitat of snakehead exacerbates the situation since the bottom region boggy water [45] zone carries 10-20 time higher bacterial population compared to the other water column [31]. Aeromonas hydrophila is an opportunistic pathogenic bacteria thrives in this habitat and produces endotoxins and haemolysins [39] and [38,40] causing epizootic ulcerative syndrome (EUS) culminating in severe ulcerations and mortality [45]. The fish diseases of $C$. striata are usually managed using antibiotics (like other fish species) which have led to antimicrobial resistant pathogens, reduction in beneficial microbiota in the gastrointestinal (GI) ecosystem, including the accumulation of residual antibiotics in fish muscle making it unsuitable for human consumption. Further, these treatments are not suitable for the management of parental disease $[24,47]$ except as nutritional therapy. Supplementation of dietary prebiotics [23] and probiotics [22] with fish diet might be a potential nutritional therapy that are used as alternatives [16] to overcome the problems associated with antibiotics. Among the positive effects of these supplements are the enhancement of growth performance, high nutrient protein digestibility, high digestive enzymes activities and high expression of immune regulatory genes [33]. Both supplements have led to direct beneficial effects of the hosts in terms of growth by improving intestinal microbial balance $[2,18]$. Dietary prebiotics and probiotics has also been shown to enhance the quality of the haematological and immunological blood parameters of snakehead [51]. To date, there is no information on the duration of effectiveness of prebiotics and probiotics for a period of post-feeding without any supplementation. Hence this study evaluated directly the influence of pre- and probiotic feed supplements on blood and immunological

\footnotetext{
* Corresponding author. Department of Aquatic Science, Faculty of Resource Science and Technology, Univeriti Malaysia Sarawak, 94300 Kota Samarahan, Sarawak, Malaysia. Tel.: +60143047193 .

E-mail address: mmbodrul@unimas.my (M.B. Munir).
} 